\title{
PRIORIDADES COMPETITIVAS PARA A ESTRATÉGIA DE OPERAÇÕES DE SERVIÇOS: UMA ANÁLISE DOS CRITÉRIOS DE VALOR PERCEBIDO DE UMA ACADEMIA DE GINÁSTICA
}

\section{COMPETITIVE PRIORITIES FOR SERVICE OPERATIONS STRATEGY: AN ANALYSIS OF THE PERCEIVED-VALUE CRITERIA OF A FITNESS CENTER}

\author{
Luciano Costa Santos* E-mail: luciano@ct.ufpb.br \\ Cláudia Fabiana Gohr* E-mail: claudiagohr@ct.ufpb.br \\ Gregorio Varvakis** E-mail: grego@deps.ufsc.br \\ *Universidade Federal da Paraíba, João Pessoa, PB \\ **Universidade Federal de Santa Catarina, Florianópolis, SC
}

\begin{abstract}
Resumo: A definição de prioridades entre os diferentes objetivos de desempenho das operações é uma das atividades principais do processo de formulação da estratégia de produção. Reconhecendo a importância dessa atividade e utilizando a nomenclatura de "critérios de valor percebido", este artigo relata uma análise das prioridades competitivas das operações de uma academia de ginástica, que foi parte essencial de um processo mais abrangente que visava à formulação da estratégia de operações da empresa. Após uma breve revisão de literatura, o artigo propõe um modelo para a análise de critérios de valor percebido em operações de serviços que, dentre outras ferramentas, faz uso da matriz importância-desempenho e da análise de trade-offs. Para validar sua aplicabilidade, o modelo proposto foi testado em campo segundo a abordagem da pesquisa-ação, na qual um dos autores desse artigo exerceu o papel de facilitador externo do processo de intervenção organizacional. A aplicação do modelo permitiu identificar os processos e os critérios de valor percebido (CVP's) que deveriam ser priorizados pela empresa, utilizando para isso, duas bases de comparação: os concorrentes diretos de sua área de influência e as academias consideradas como referências em sua região (melhores práticas). Como resultado, os gerentes da empresa puderam visualizar as diferentes alternativas estratégicas para a melhoria de suas operações.
\end{abstract}

Palavras-chave: Estratégia de operações. Operações de serviços. Critérios de valor percebido.

Abstract: The setting of priorities among the various performance objectives is one of the main activities in the formulation of manufacturing strategy. Recognizing the importance of this activity and using the nomenclature of "perceived-value criteria", this paper reports an analysis of competitive priorities of a fitness center, which was an essential part of a broader process aimed at the formulation of operations strategy for the company. After a brief literature review, the article proposes a model for the analysis of perceived-value criteria in service operations that, among other tools, makes use of importance-performance matrix and trade-off analysis. To validate its applicability, the proposed model was field-tested in an action research approach, in which one of the authors of this paper played the role of external facilitator of the process of organizational intervention. The application of the model allowed identifying the processes and the perceived-value criteria (PVC's) that should be prioritized by the company, using for this, two bases of comparison: the direct competitors of its influence area and the benchmark fitness centers (best practices). As a result, the firm's managers were able to better decide about the different strategic alternatives to improve its operations.

Key-words: Operations strategy. Service operations. Perceived-value criteria. 


\section{INTRODUÇÃO}

A definição dos objetivos de desempenho das operações, bem como o estabelecimento de prioridades entre os diferentes objetivos, costuma ser uma das principais preocupações das empresas durante o processo de formulação da estratégia de produção (JIA; BAI, 2011; LIMA; COSTA; FARIA, 2009; SLACK; LEWIS, 2009). A estratégia de operações, que normalmente é vista como o elo que liga a estratégia competitiva à gestão da produção (SKINNER, 2007), começa a ser traçada a partir do momento em que são definidas as prioridades competitivas das operações, sejam elas prioridades de custo, qualidade, rapidez ou flexibilidade. Desse modo, a estratégia competitiva poderá ser entendida e traduzida para a realidade do subsistema de produção, de forma que ele possa contribuir para realização dos objetivos de um sistema organizacional de mais amplo escopo.

Geralmente, o desdobramento da estratégia competitiva para a estratégia de produção passa pela tradução dos requisitos de mercado (objetivos externos) em objetivos de desempenho para as operações (objetivos internos). Por exemplo, em algumas empresas o requisito "rapidez de entrega" tem sido traduzido como "redução do lead time do processo produtivo". Seguindo essa lógica, o processo tradicional de formulação da estratégia de produção parte da visão orientada pelo mercado, na qual a estratégia é guiada de "fora para dentro".

Assim como acontece na indústria de manufatura, a necessidade de desdobrar a estratégia competitiva para a estratégia de produção também tem sido defendida no setor de serviços, embora seja necessário levar em consideração as diferenças entre as operações de serviços e as operações de manufatura (SAMPSON; FROEHLE, 2006). Dentre essas diferenças, destaca-se o fato de o cliente participar do processo de produção, ou seja, ele está no centro do sistema de operações de serviços. Nesse sentido, os critérios competitivos das operações de serviços dispensam a distinção entre objetivos externos e internos, uma vez que o cliente (externo) faz parte do sistema de operações (interno). Em serviços, os requisitos do cliente são os mesmos objetivos que devem ser perseguidos pelas operações, não havendo a necessidade da tradução "externo-interno". Por esse motivo, torna-se importante tratar os objetivos de desempenho em serviços de uma forma unificada e com uma nomenclatura adequada. Portanto, os critérios 
competitivos foram tratados neste trabalho como critérios de valor percebido, seguindo a mesma linha conceitual de Roth e Menor (2003) e Lin, Sher e Shih (2005).

Utilizando essa nomenclatura, este artigo relata uma análise dos critérios de valor percebido de uma academia de ginástica, que foi parte essencial de um processo mais abrangente que objetivava a formulação da estratégia de operações da empresa. Apesar de ter uma situação financeira relativamente estável, a academia estudada enfrentava os mesmos problemas da maioria das empresas ligadas ao setor de fitness, como a sazonalidade da demanda e a visão que o mercado tem da atividade física como uma atividade supérflua, o que torna as academias muito sensíveis a crises econômicas. Conscientes das turbulências em seu setor de atuação, os sócios-gerentes da empresa tinham a intenção de melhorar seus procedimentos de planejamento, estabelecendo prioridades para operações da academia. Essa necessidade foi demonstrada pelos gerentes no contato inicial com os autores desse trabalho e os motivou a participar do projeto de pesquisa que thes foi proposto.

Para a execução da pesquisa de campo, foram aplicadas diferentes ferramentas de estratégia de produção nas operações da academia, tais como, a matriz importância-desempenho e a análise de trade-offs. Essas ferramentas foram organizadas em torno de um modelo de referência que foi proposto para a análise dos critérios de valor percebido em operações de serviços, o que, por si só, constituiu uma das contribuições deste trabalho. A aplicação do modelo permitiu identificar os processos e os critérios de valor percebido (CVP's) que deveriam ser priorizados pela empresa, utilizando para isso, duas bases de comparação: os concorrentes diretos de sua área de influência e as academias consideradas como referências em sua região (melhores práticas).

Após uma breve revisão de literatura, o artigo descreve um modelo para a análise de critérios de valor percebido em operações de serviços. Em seguida, apresentam-se os procedimentos metodológicos que guiaram a coleta e a análise de dados. A aplicação do modelo proposto na academia de ginástica é relatada na seção posterior, destacando os principais resultados da pesquisa de campo. $O$ texto é encerrado com as considerações finais sobre o trabalho realizado. 


\section{ESTRATÉGIA DE OPERAÇÕES E PRIORIDADES COMPETITIVAS}

A maioria dos autores da área de estratégia de produção a descreve por meio de dois conceitos inter-relacionados: conteúdo e processo (SLACK; LEWIS, 2009; DANGAYACH; DESHMUKH, 2001). Enquanto o conteúdo se refere aos elementos que constituem a estratégia de operações, o processo se refere ao modo que esses elementos são formados. Em outras palavras, o processo constrói o conteúdo, e o conteúdo resulta da interação entre as prioridades competitivas e as decisões estratégicas no âmbito das operações.

Desde o trabalho pioneiro de Skinner (1969), diversos autores têm definido conjuntos genéricos de objetivos de desempenho, de forma a detalhar a estratégia competitiva da organização para a tarefa que as operações são responsáveis por desempenhar. Um conjunto genérico que reflete a maioria dos objetivos de desempenho apresentados pelos autores da área é sugerido por Slack e Lewis (2009), que apresentam cinco objetivos para as operações: qualidade, rapidez, confiabilidade, flexibilidade e custo.

Obviamente, cada empresa tem a liberdade de definir seu próprio conjunto de objetivos de desempenho, levando em consideração as particularidades de cada negócio. Para atender às peculiaridades de cada organização, Garvin (1993) sugere que os objetivos de desempenho passem por um processo de "desagregação", que consiste em refinar os critérios genéricos em categorias mais específicas. Nesse refinamento, por exemplo, o objetivo "flexibilidade" poderia ser subdividido em flexibilidade de volume, flexibilidade de processo e flexibilidade de produto, de acordo com as características do sistema de operações que fosse analisado.

Entretanto, apenas conhecer os objetivos de desempenho não é suficiente, pois ainda é necessário definir quais objetivos são prioritários. Para isso, é fundamental compreender a importância que o mercado atribui a cada fator competitivo. Com essa intenção, Hill (1994) criou uma maneira prática para classificar um critério competitivo de acordo com sua importância relativa, dividindo os diferentes fatores em critérios ganhadores de pedidos e critérios qualificadores. Um critério competitivo pode ser considerado "ganhador de pedidos" quando ele contribui significativamente para a decisão de compra do cliente. Os critérios ganhadores de pedidos correspondem aos principais motivos que levam o cliente a 
preferir um produto de uma determinada empresa em relação aos produtos da concorrência. Os critérios "qualificadores", por sua vez, são aqueles nos quais a empresa deve estar acima de um padrão mínimo para poder competir no mercado. Quando um critério desse tipo está abaixo do nível qualificador, o cliente nem considera o produto da empresa como uma opção de escolha.

A classificação de Hill (1994) representou uma contribuição sólida para o conhecimento sobre estratégia de produção e tem sido objeto de pesquisa em diversos trabalhos na área (SILVEIRA, 2005; SPRING; BOADEN, 1997). A definição da importância relativa dos critérios competitivos também serviu de inspiração para o desenvolvimento de ferramentas práticas para a formulação da estratégia de operações. Slack (1994), por exemplo, se baseou na classificação de critérios de Hill (1994) para estruturar uma das mais conhecidas ferramentas de priorização da estratégia de operações: a matriz importância-desempenho.

Para a operacionalização da matriz importância-desempenho, Slack (1994) criou duas escalas de nove pontos: uma para a avaliação da importância do critério para o cliente e outra para a avaliação do desempenho da empresa em relação à concorrência. Com base na escala proposta, os critérios competitivos são avaliados e os resultados são posicionados na matriz. A prioridade de melhoria dos diferentes objetivos de desempenho é estabelecida de acordo com a região da matriz em que se encontrar cada critério (“adequado", "melhorar", "ação urgente” ou "excesso?”).

De fato, a análise importância-desempenho não é algo novo e tem sido difundida há bastante tempo na literatura acadêmica, desde o trabalho seminal de Martilla e James (1977). No entanto, a lógica da análise importância-desempenho ainda constitui um dos fundamentos para a priorização de critérios e continua sendo aplicada em diferentes situações e em diferentes contextos (ARBORE; BUSACCA, 2011; RIVIEZZO; NISCO; NAPOLITANO, 2009; DENG; KUO; CHEN, 2008; TONTINI; SILVEIRA, 2007).

Embora a análise importância-desempenho já existisse na época em que a matriz de Slack (1994) foi criada, o autor foi responsável por incorporar essa ideia no processo de formulação da estratégia de produção, desenvolvendo uma ferramenta que permanece útil e inalterada até hoje (SLACK; LEWIS, 2009). Aproveitando a contribuição que já havia sido feita pelo tradicional modelo de Platts e Gregory (1990), a matriz importância-desempenho de Slack (1994) está fundamentada na 
noção de gaps (lacunas) entre o desempenho atual e o desempenho desejado das operações. A definição de prioridades por meio da identificação de lacunas de desempenho permite que a formulação da estratégia seja vista como uma atividade de melhoria contínua das operações.

A priorização dos objetivos de desempenho está relacionada com o conceito de trade-off, originalmente introduzido na literatura de estratégia de operações por Skinner (1969). O conceito de trade-off parte da premissa que dificilmente uma empresa poderá ser excelente em todos os objetivos de desempenho. Assim, a prioridade em um objetivo pode sacrificar a prioridade em outro, como pode acontecer, por exemplo, no tradicional conflito (trade-off) entre qualidade e custo. Em consequência disso, os gerentes de produção podem ser impelidos a assumir compromissos que os levam a "trocar" uma prioridade por outra, pois eles partem do princípio de que existem trade-offs entre os diferentes objetivos de desempenho.

Mesmo que em algumas vezes a melhoria de um critério possa fazer decair o desempenho de outro, em outras situações pode ocorrer justamente o oposto: acontece quando dois ou mais critérios possuem sinergia e a melhoria de um pode naturalmente acarretar a melhoria de outro(s), fenômeno observado há bastante tempo por Ferdows e De Meyer (1990) ao defender o conhecido modelo do "cone de areia". Independentemente do debate acadêmico sobre a existência ou não de trade-offs (ROSENZWEIG; EASTON, 2010), a prática sugere uma visão integrativa (LIU; ROTH; RABINOVICH, 2011; HALLGREN; OLHAGER; SCHROEDER, 2011; BOYER; LEWIS, 2002), na qual a formulação da estratégia de operações deve considerar tanto as relações conflitantes (trade-offs) quanto as relações de apoio mútuo entre os critérios competitivos.

Os objetivos de desempenho priorizados para as operações são de fato realizados por meio do padrão das decisões estratégicas que são tomadas. Como sugere a literatura tradicional de estratégia de produção, as decisões estratégicas das operações podem ser agrupadas em áreas de decisão estruturais e áreas de decisão infraestruturais (HAYES et al., 2005). Na verdade, as áreas de decisão, sejam estruturais ou infraestruturais, correspondem a subfunções da função produção, como por exemplo: PCP, engenharia do produto, controle de qualidade, etc. Uma visão alternativa propõe o agrupamento das decisões estratégicas de acordo com os processos empresarias, ao invés de uma lista de subfunções da Revista Produção Online. Florianópolis, SC, v.12, n. 1, p. 133-158, jan./mar. 2012. 
produção (ACUR; BITITCI, 2003). Assim, o conteúdo da estratégia de produção passa a ser definido pelas inter-relações entre as prioridades competitivas e os processos-chave das operações.

A breve revisão de literatura apresentada nesta seção forneceu a base conceitual para a proposição de um modelo de análise, apresentado a seguir.

\section{MODELO PROPOSTO}

Para a análise dos critérios competitivos das operações de serviços, foi proposto um modelo de referência, apresentado na figura 1. Conforme foi explicado anteriormente, o modelo proposto utiliza a nomenclatura de "critérios de valor percebido", ou simplesmente, CVP's.

Figura 1 - Modelo para análise dos critérios de valor percebido.

\begin{tabular}{|c|c|c|c|c|c|c|}
\hline & & Análise dos & ritérios de $\mathrm{Va}$ & r Percebido & & Saídas \\
\hline $\begin{array}{l}\text { concorrência } \\
\text { - Informações sobre a } \\
\text { percepção dos clientes } \\
\text { - Informações sobre os } \\
\text { processos de serviços }\end{array}$ & $\begin{array}{ll}\text { Definir } & 1 \\
\text { critérios de } \\
\text { valor } \\
\text { percebido }\end{array}$ & $\begin{array}{l}\text { Analisar a } \\
\text { concorrência }\end{array}$ & $\begin{array}{l}\text { Analisar a } \\
\text { matriz } \\
\text { importância- } \\
\text {-desempenho }\end{array}$ & $\begin{array}{l}\text { Analisar as } \\
\text { relacões entre } \\
\text { critérios }\end{array}$ & $\begin{array}{l}{ }^{5} \\
\text { Correlacionar } \\
\text { critérios com } \\
\text { processos }\end{array}$ & $\begin{array}{l}\text { Trade-offs e relações } \\
\text { de apoio mútuo } \\
\text { identificadas } \\
\text { - Prioridades de } \\
\text { melhoria definidas }\end{array}$ \\
\hline
\end{tabular}

Fonte: Elaborado pelos autores.

O primeiro passo da análise de CVP's consiste na definição de critérios que são específicos para a empresa. O ponto de partida para essa atividade é um conjunto genérico de nove critérios comuns às operações de serviços: confiabilidade, rapidez, flexibilidade, competência, empatia, tangíveis, acesso, disponibilidade e preço. Essa lista de requisitos genéricos foi obtida pela compilação de dimensões de serviços propostas por vários autores, dentre eles: Fitzsimmons e Fitzsimmons (2005), Corrêa e Caon (2002), Johnston (1995) e Parasuraman, Zeithaml e Berry (1985).

A partir de cada critério genérico, devem-se obter critérios específicos para a empresa, traduzidos para a linguagem e para as peculiaridades das operações que estão sendo analisadas. Esse processo toma como base o princípio da “desagregação”, proposto por Garvin (1993).

A definição dos CVP's fornece parâmetros para a análise da concorrência, o próximo passo do procedimento. Para isso, são selecionados os principais Revista Produção Online. Florianópolis, SC, v.12, n. 1, p. 133-158, jan./mar. 2012. 
concorrentes diretos da empresa, que deverão ser avaliados em relação aos CVP's que foram definidos. Os resultados são organizados em um quadro comparativo que apresenta o desempenho da empresa e o desempenho dos concorrentes selecionados. Para a avaliação dos critérios, sugere-se utilizar uma escala de cinco pontos (Likert) do tipo: Excelente - Bom - Regular - Ruim - Péssimo.

Em seguida, é feita a análise importância-desempenho por meio da matriz proposta por Slack (1994). Inicialmente, cada CVP é avaliado de acordo com as escalas de importância e desempenho apresentadas no quadro 1. Na avaliação do desempenho em relação à concorrência, os resultados da atividade anterior (análise da concorrência) podem atuar como dados de entrada para essa tarefa.

Quadro 1 - Escalas de importância e desempenho.

\begin{tabular}{|c|c|c|c|}
\hline \multirow{3}{*}{$\begin{array}{l}\text { IMPORTÂNCIA } \\
\text { PARA O CLIENTE }\end{array}$} & $\begin{array}{l}\text { Ganhadores } \\
\text { de clientes }\end{array}$ & $\begin{array}{l}\text { Forte } \\
\text { Médio } \\
\text { Fraco }\end{array}$ & $\begin{array}{l}1 \text { Proporciona uma vantagem crucial } \\
2 \text { Proporciona uma vantagem importante } \\
3 \text { Proporciona uma vantagem útil }\end{array}$ \\
\hline & Qualificadores & $\begin{array}{l}\text { Forte } \\
\text { Médio } \\
\text { Fraco }\end{array}$ & $\begin{array}{l}4 \text { Precisa estar dentro do bom padrão do setor } \\
5 \text { Precisa estar dentro do padrão médio do setor } \\
6 \text { Precisa estar a pouca distância atrás do resto do setor }\end{array}$ \\
\hline & Menos importantes & $\begin{array}{l}\text { Forte } \\
\text { Médio } \\
\text { Fraco }\end{array}$ & $\begin{array}{l}7 \text { Não usualmente de importância, mas pode tornar-se importante } \\
8 \text { Muito raramente considerado pelos clientes } \\
9 \text { Nunca considerado pelos clientes }\end{array}$ \\
\hline \multirow{3}{*}{$\begin{array}{l}\text { DESEMPENHO } \\
\text { EM RELAÇÃO À } \\
\text { CONCORRÊNCIA }\end{array}$} & $\begin{array}{l}\text { Melhor que os } \\
\text { concorrentes }\end{array}$ & $\begin{array}{l}\text { Forte } \\
\text { Médio } \\
\text { Fraco }\end{array}$ & $\begin{array}{l}1 \text { Consideravelmente melhor do que os concorrentes } \\
2 \text { Claramente melhor do que os concorrentes } \\
3 \text { Marginalmente melhor do que os concorrentes }\end{array}$ \\
\hline & $\begin{array}{c}\text { Igual aos } \\
\text { concorrentes }\end{array}$ & $\begin{array}{l}\text { Forte } \\
\text { Médio } \\
\text { Fraco }\end{array}$ & $\begin{array}{l}4 \text { Algumas vezes marginalmente melhor do que os concorrentes } \\
5 \text { Mais ou menos igual à maioria de seus concorrentes } \\
6 \text { Levemente abaixo da média da maioria }\end{array}$ \\
\hline & $\begin{array}{l}\text { Pior que os } \\
\text { concorrentes }\end{array}$ & $\begin{array}{l}\text { Forte } \\
\text { Médio } \\
\text { Fraco }\end{array}$ & $\begin{array}{l}7 \text { Usualmente marginalmente pior do que os concorrentes } \\
8 \text { Usualmente pior do que os concorrentes } \\
9 \text { Consistentemente pior do que os concorrentes }\end{array}$ \\
\hline
\end{tabular}

Fonte: Adaptado de Slack (1994).

É importante observar que, para adequar a nomenclatura da matriz importância-desempenho para as operações de serviços, os critérios "ganhadores de pedidos" foram renomeados como critérios ganhadores de clientes. Já os outros elementos permaneceram iguais à ferramenta original.

Após a avaliação da importância e do desempenho pela escala indicada, cada critério deve ser posicionado na matriz exemplificada na figura 2, permitindo a identificação das prioridades de melhoria para as operações.

Revista Produção Online. Florianópolis, SC, v.12, n. 1, p. 133-158, jan./mar. 2012. 
Figura 2 - Matriz importância-desempenho

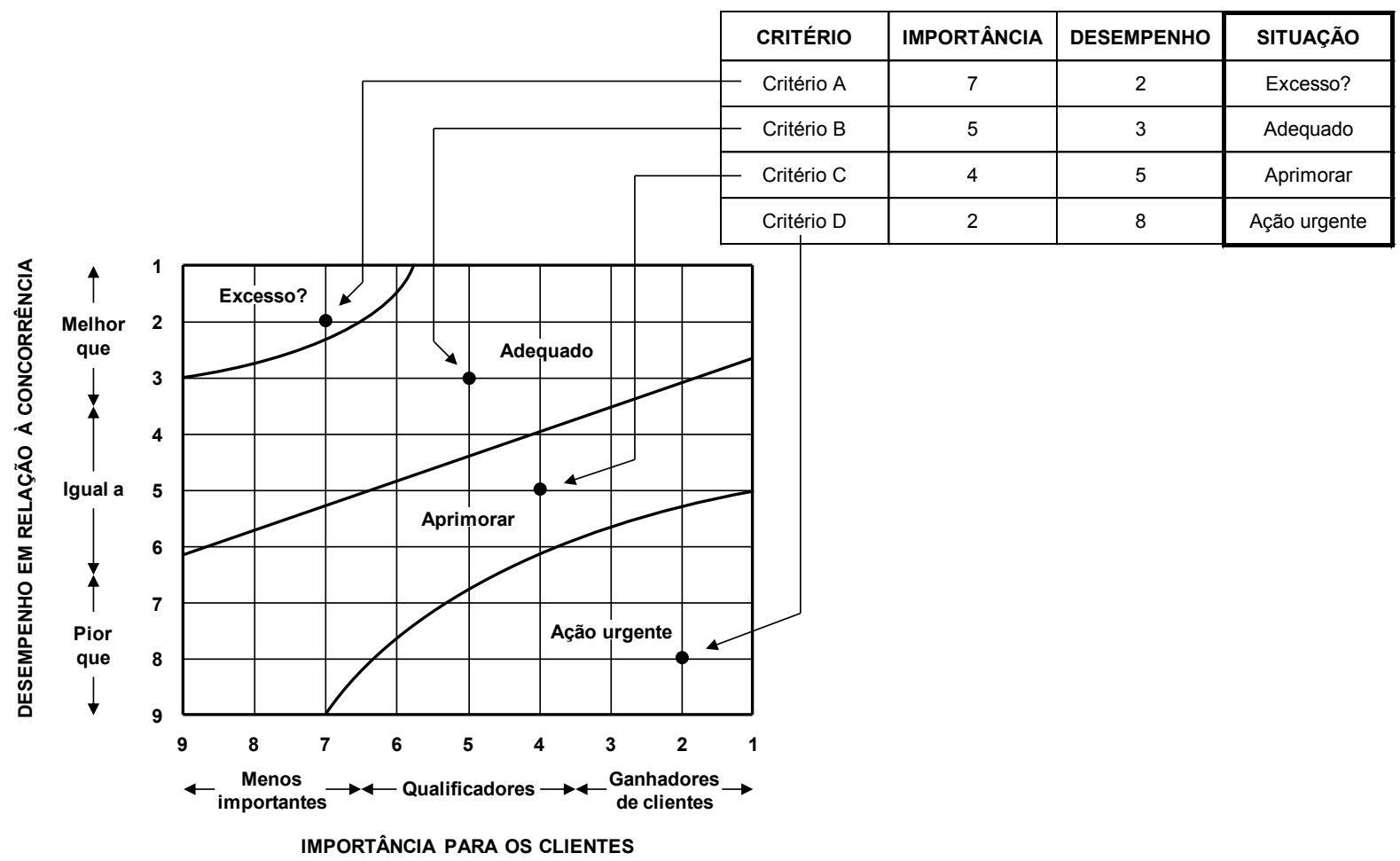

Fonte: Adaptado de Slack (1994).

Para cada área da matriz importância-desempenho, pode-se fazer a seguinte interpretação:

- "Ação urgente": o critério precisa de uma melhoria imediata (curto prazo).

- "Aprimorar": o critério necessita de uma melhoria em médio prazo.

- "Adequado": os critérios estão adequados no momento, mas devem ser monitorados.

- "Excesso?": é necessário investigar se está havendo desperdício de recursos para melhorar algo que cliente não valoriza. O ponto de interrogação demonstra que o "excesso" não é necessariamente uma constatação, mas é algo que deve ser investigado.

O próximo passo da análise é identificar possíveis trade-offs e também relações de apoio mútuo entre os diferentes CVP's. Para isso, utiliza-se uma matriz de relações que permite uma análise cruzada entre os critérios. Para cada cruzamento entre dois critérios, deve-se assinalar um " $X$ " para uma relação conflitante (trade-off) e um "O" para uma relação de apoio mútuo. Se não houver nenhuma relação, deve-se deixar a célula da matriz em branco. 
O reconhecimento das relações conflitantes e de apoio mútuo traz um auxílio importante quando se analisa a viabilidade de novas estratégias de operações. Em alguns casos, podem existir dois critérios que têm uma prioridade de melhoria urgente, determinada pela análise importância-desempenho, mas que demonstram ter uma relação de trade-off. Nessa situação, o gerente de serviços se vê obrigado a fazer uma escolha, seja mudando o foco de seu serviço ou buscando soluções inovadoras que são capazes de desfazer o conflito. Também pode acontecer de haver um investimento acima do normal em um critério que se encontra na zona de "Excesso?" da matriz, e que ainda assim, os gerentes chegam à conclusão que é necessário manter esse investimento, pois o CVP tem uma relação de apoio mútuo e ajuda a "alavancar" outro critério que é prioritário para o cliente.

Para finalizar a análise de CVP's, é necessário entender como os diferentes processos de serviços podem contribuir para cada critério. Além de identificar os critérios que necessitam de melhoria, é importante descobrir os possíveis caminhos para isso, pois a melhoria das operações somente acontece por meio de seus processos. Com esse objetivo, uma matriz é utilizada para visualizar as relações entre critérios e processos, representadas por símbolos que significam "relação forte", "relação média" e "relação fraca". Quando não houver nenhuma relação entre um critério e um processo qualquer, a célula da matriz deve ficar em branco.

Após a definição das relações critério-processo, é interessante incrementar a análise com os resultados da matriz importância-desempenho. Se existem critérios que têm prioridade de melhoria, os processos relacionados com esses critérios também terão prioridade de melhoria. Para identificar os processos prioritários, podem-se atribuir pontuações ponderadas na matriz critério-processo. Nesse caso, os resultados da matriz importância-desempenho servem de referência para a definição dos pesos (sugerem-se: peso 3 para "Ação urgente", peso 2 para "Aprimorar", peso 1 para "Adequado", peso 1 para "Excesso?"). Já para a definição das pontuações (ou notas), pode-se utilizar uma escala geralmente adotada em matrizes de QFD (Quality Function Deployment): 9 pontos para relação forte, 3 pontos para relação média e 1 ponto para relação fraca.

Assim, após a construção das matrizes critério-processo (simples e ponderadas), é possível visualizar os processos que devem ser melhorados para 
atingir o desempenho desejado nos CVP's. Com este último passo, completa-se a análise dos critérios de valor percebido, ilustrada pelo modelo da figura 1.

\section{PROCEDIMENTOS METODOLÓGICOS PARA A APLICAÇÃO}

Do ponto de vista da metodologia científica, pode-se afirmar que a aplicação do modelo seguiu a abordagem da pesquisa-ação, um método que tem sido aconselhado em pesquisas na área de gestão de operações (COUGHLAN; COGHLAN, 2002). Na pesquisa-ação o pesquisador intervém na realidade organizacional e envolve o objeto pesquisado para o alcance dos objetivos da pesquisa (EDEN; HUXHAM, 1996). O envolvimento entre os pesquisadores e o objeto pesquisado ocorreu por meio da aplicação do modelo proposto, que foi testado in loco.

A equipe de pesquisa-ação foi composta por quatro pessoas: os dois sóciosgerentes da academia, um pesquisador (facilitador externo) e um bolsista de iniciação científica, que auxiliou na coleta de dados internos e externos. Durante o processo de pesquisa, a equipe se reunia periodicamente para analisar os dados que haviam sido coletados e discutir as possíveis alternativas estratégicas para a empresa, já que a análise dos CVP's era uma das etapas do processo de formulação da estratégia de operações da academia, conforme foi mencionado anteriormente.

A unidade de análise na pesquisa de campo foi definida de acordo com a proposição de Acur e Bititci (2003), na qual a unidade de análise na perspectiva da estratégia de operações corresponde aos processos operacionais e aos processos de suporte, equivalendo em serviços, aos processos de linha de frente e de retaguarda. Durante a pesquisa, o próprio modelo que foi aplicado funcionou como um roteiro geral de coleta de dados, abrangendo o escopo dos processos de serviços da empresa.

Como fonte de dados secundários referentes à percepção dos clientes, a academia dispunha de uma "pesquisa de satisfação" que tinha sido realizada recentemente com uma amostra representativa de alunos matriculados. Além dos dados de satisfação do cliente em relação aos serviços prestados, a pesquisa trazia várias informações que caracterizavam o perfil da clientela da academia. Como os 
parâmetros estabelecidos e as variáveis medidas por aquela pesquisa se ajustavam perfeitamente ao tipo de informação que era necessária para a análise dos CVP's, a equipe considerou que não havia necessidade de realizar uma segunda pesquisa para a coleta de dados primários dos clientes. No entanto, a equipe ainda precisava complementar as informações que já tinha sobre os concorrentes da empresa e, por isso, coletou dados primários com esta finalidade.

Além da coleta de dados externos, a percepção dos gerentes também foi levada em consideração para realizar as atividades necessárias para a aplicação do modelo. Como os sócios-gerentes conheciam todos os processos da academia, eles tinham plenas condições de fornecer e avaliar os dados internos da empresa.

Os demais procedimentos de coleta e análise de dados que não foram detalhados aqui são descritos concomitantemente à narrativa da aplicação do modelo.

\section{APLICAÇÃO DO MODELO EM UMA ACADEMIA DE GINÁSTICA}

A academia de ginástica selecionada para a aplicação do modelo apresentava as principais características presentes na maioria das operações de serviços (intangibilidade, simultaneidade e participação), tendo o foco predominante nos processos de linha de frente. Pelo fato de o trabalho realizado envolver questões estratégicas, optou-se por não divulgar o nome da empresa, omitindo todos os dados que pudessem identificar a organização.

Possuindo instalações modernas, a academia estava localizada nas dependências de um shopping center de uma grande cidade, o que lhe conferia o status das academias de shopping. Essas características influenciavam no perfil de sua clientela, que era composta basicamente de pessoas das classes A e B. $\mathrm{O}$ volume de clientes da academia variava de 400 a 700 alunos matriculados, de acordo com a época do ano. Como em qualquer negócio desse setor, a procura por atividades físicas aumentava nos meses que antecedem o verão, sendo também influenciada pelas condições climáticas de cada ano.

O pequeno porte da empresa facilitava na agilidade para a tomada de decisões. Todas as decisões estratégicas eram tomadas pelos dois proprietários, que possuíam a vantagem de conhecer de perto os problemas da linha de frente, 
pois eles também trabalhavam em contato direto com o cliente. Apesar disso, a academia tinha dificuldades para realizar um planejamento formal, um dos fatores que motivaram a sua participação nesta pesquisa. A aplicação de cada uma das etapas do modelo é apresentada a seguir.

\subsection{Definição dos critérios de valor percebido}

Para a realização desta atividade, a equipe procurou definir o que cada um dos critérios genéricos significava especificamente para as operações da academia. Como mostra o quadro 2, alguns critérios genéricos foram divididos em mais de um critério específico.

Quadro 2 - Critérios de valor percebido da academia.

\begin{tabular}{|c|c|}
\hline CRITÉRIOS GENÉRICOS & CRITÉRIOS ESPECÍFICOS \\
\hline Confiabilidade & Agilidade no atendimento \\
\hline Rapidez & $\begin{array}{c}\text { Flexibilidade de horário } \\
\text { Personalização }\end{array}$ \\
\hline Flexibilidade & \begin{tabular}{c} 
Competência dos instrutores \\
\hline Competência
\end{tabular} \\
\hline Empatia & $\begin{array}{c}\text { Empatia dos instrutores } \\
\text { Empatia na recepção }\end{array}$ \\
\hline Tangiveis & $\begin{array}{c}\text { Higiene \& Limpeza } \\
\text { Ambiente físico } \\
\text { Conforto dos equipamentos }\end{array}$ \\
\hline Acesso & Acesso físico \\
\hline Disponibilidade & $\begin{array}{c}\text { Disponibilidade de equipamentos } \\
\text { Disponibilidade de instrutores }\end{array}$ \\
\hline Preço & Preço \\
\hline
\end{tabular}

Fonte: Elaborado pelos autores

A equipe chegou à lista final de 14 CVP's (quadro 2) com base em duas fontes de informação: a percepção dos gerentes e a pesquisa de satisfação que havia sido realizada, que já avaliava a maior parte dos critérios que fizeram parte da lista. Além disso, a definição dos critérios também foi influenciada pelos resultados da pesquisa publicada por Mello, Leão e Souza Neto (2005), que avaliou o processo de escolha do consumidor em academias de ginástica e restaurantes fast-food. Alguns dos atributos de escolha em academias que foram considerados na pesquisa desses autores são equivalentes aos CVP's que foram estabelecidos nesta análise.

Revista Produção Online. Florianópolis, SC, v.12, n. 1, p. 133-158, jan./mar. 2012. 
Os critérios de valor percebido foram definidos dentro da ótica de avaliação do cliente e unia naturalmente a perspectiva do cliente à perspectiva das operações.

\subsection{Análise da concorrência}

Após a definição dos critérios de valor percebido, a equipe passou a dispor de parâmetros de comparação para que fosse feita a análise da concorrência. Porém, antes dessa análise, era preciso definir quais eram os principais concorrentes diretos da empresa. Para isso, foi utilizado o conceito de área de influência, muito comum no setor de varejo, mas que também pode ser aplicado às academias de ginástica. $A$ área de influência é delimitada pela região geográfica que uma empresa abrange, considerando que grande parte dos clientes dessa empresa está situada dentro dessa área (PARENTE; KATO, 2001). Além da empresa em análise, foram identificadas quatro academias em sua área de influência, sendo que três foram selecionadas para a pesquisa (denominadas como "Concorrente A", "Concorrente B" e "Concorrente C", por questões de sigilo).

A coleta de dados sobre as academias concorrentes foi feita por meio da técnica do "cliente fantasma", também conhecida como "cliente oculto" ou "comprador misterioso". Na técnica do cliente fantasma, o pesquisador se faz passar por um cliente (usuário ou potencial) da empresa a ser analisada, com a intenção de avaliar diferentes aspectos de um serviço (WILSON, 1998; KOCEVAR-WEIDINGER et al., 2010). Para isso, um dos integrantes da equipe, que nunca tinha estado em nenhuma das empresas anteriormente, assumiu o papel de um cliente que estaria procurando uma academia para frequentar. Então, para cada empresa avaliada, o "cliente fantasma" da equipe telefonava para a academia pedindo informações, visitava as instalações, conversava com os professores mostrando interesse nas atividades e participava de aulas experimentais que the fossem oferecidas. Depois da experiência vivenciada em cada academia, o cliente fantasma fazia anotações gerais sobre tudo que tinha observado e também anotações específicas sobre as suas impressões quanto ao desempenho da empresa em cada critério. A análise do "cliente fantasma" foi somada às informações que a empresa já possuía, resultando nas informações apresentadas no quadro 3. 
Quadro 3 - Análise comparativa dos principais concorrentes da academia (área de influência).

\begin{tabular}{|l|c|c|c|c|}
\hline \multicolumn{1}{|c|}{ CRITÉRIOS } & NOSSA EMPRESA & CONCORRENTE A & CONCORRENTE B & CONCORRENTE C \\
\hline Preço & Bom & Excelente & Bom & Regular \\
\hline Acesso físico & Excelente & Péssimo & Regular & Regular \\
\hline Disponibilidade de equipamentos & Excelente & Péssimo & Excelente & Bom \\
\hline Disponibilidade de instrutores & Excelente & Regular & Regular & Bom \\
\hline Empatia dos instrutores & Bom & Regular & Bom & Bom \\
\hline Competência dos instrutores & Excelente & Excelente & Excelente & Excelente \\
\hline Agilidade no atendimento & Excelente & Péssimo & Excelente & Excelente \\
\hline Empatia na recepção & Excelente & Bom & Excelente & Excelente \\
\hline Higiene \& Limpeza & Excelente & Péssimo & Excelente & Ruim \\
\hline Segurança dos equipamentos & Excelente & Péssimo & Bom & Regular \\
\hline Conforto dos equipamentos & Excelente & Péssimo & Bom & Regular \\
\hline Flexibilidade de horário & Bom & Ruim & Bom & Ruim \\
\hline Personalização & Bom & Regular & Bom & Bom \\
\hline Ambiente físico & Excelente & Péssimo & Bom & Ruim \\
\hline
\end{tabular}

Fonte: Elaborado pelos autores.

Na análise da concorrência, a empresa demonstrou um desempenho superior em quase todos os critérios de valor percebido. Somente no critério "preço", a empresa teve uma avaliação pior que a do "Concorrente A", o que é justificável, por se tratar de um concorrente que adota uma típica estratégia competitiva de baixo custo, priorizando o preço baixo e sacrificando os demais critérios (trade-off). De um modo geral, pôde-se afirmar que a academia ocupava uma posição de liderança em sua área de influência, adotando uma estratégia de diferenciação.

\subsection{Análise importância-desempenho}

A análise da concorrência forneceu uma boa base para a construção da matriz importância-desempenho. Porém, como a academia tinha apresentado um desempenho claramente superior ao da concorrência local, os gerentes demonstraram a intenção de equiparar a empresa às melhores academias de sua região metropolitana, que vai além de sua área de influência.

Assim, foi decidido que seriam elaboradas duas matrizes, uma em relação à área de influência e outra em relação às melhores academias da região. Porém, 
para a segunda matriz não haveria uma coleta de dados "in loco", como aquela que foi feita para os concorrentes da área de influência. Pela experiência que os gerentes possuíam, eles saberiam identificar facilmente quais eram as academias consideradas como referências na região (melhores práticas). Eles conheciam pessoalmente essas academias e seus proprietários, de modo que eles teriam condições de avaliar o desempenho da empresa em relação às melhores práticas com uma segurança razoável, embora essa análise envolvesse um certo grau de julgamento pessoal.

$\mathrm{Na}$ avaliação do grau de importância para o cliente, mais uma vez foram utilizados os dados da pesquisa de satisfação, que já sinalizava esse tipo de informação. Devido à semelhança dos resultados dessa pesquisa com os resultados do estudo de Mello, Leão e Souza Neto (2005) sobre os atributos de escolha do cliente, a equipe decidiu adotar os mesmos graus de importância, tanto para a área de influência quanto para as melhores da região. Então, cada CVP foi avaliado utilizando a escala sugerida no quadro 1 . Os resultados dessa análise são apresentados no quadro 4 e posicionados nas matrizes das figuras 3 e 4 .

Os resultados da análise importância-desempenho confirmaram posição de liderança da academia em relação aos concorrentes de sua área de influência, sendo que todos os critérios de valor percebido ficaram situados na zona "adequada" da primeira matriz. Como o preço ainda era um pouco maior do que o dos concorrentes diretos, esse critério ficou no limite entre o "adequado" e o "aprimoramento". No entanto, foi possível afirmar que o preço que a academia praticava era coerente com a sua estratégia de diferenciação. 
Quadro 4 - Pontuação de importância e desempenho da academia.

\begin{tabular}{|l|c|c|c|}
\hline \multirow{2}{*}{ CRITÉRIOS DE VALOR PERCEBIDO } & \multirow{2}{*}{ IMPORTÂNCIA } & \multicolumn{2}{c|}{ DESEMPENHO } \\
\cline { 3 - 4 } & & Área de influência & Melhores da região \\
\hline Preço & 4 & 4 & 1 \\
\hline Acesso físico & 2 & 1 & 6 \\
\hline Disponibilidade de equipamentos & 1 & 3 & 5 \\
\hline Disponibilidade de instrutores & 2 & 3 & 3 \\
\hline Empatia dos instrutores & 2 & 2 & 5 \\
\hline Competência dos instrutores & 2 & 2 & 5 \\
\hline Agilidade no atendimento & 4 & 2 & 5 \\
\hline Empatia na recepção & 3 & 1 & 5 \\
\hline Higiene \& Limpeza & 4 & 1 & 5 \\
\hline Segurança dos equipamentos & 5 & 1 & 5 \\
\hline Conforto dos equipamentos & 5 & 3 & 5 \\
\hline Flexibilidade de horário & 4 & 2 & 5 \\
\hline Personalização & 2 & 1 & 5 \\
\hline Ambiente físico & 2 & 2 & \\
\hline
\end{tabular}

Fonte: Elaborado pelos autores.

Figura 3 - Matriz importância-desempenho (área de influência).

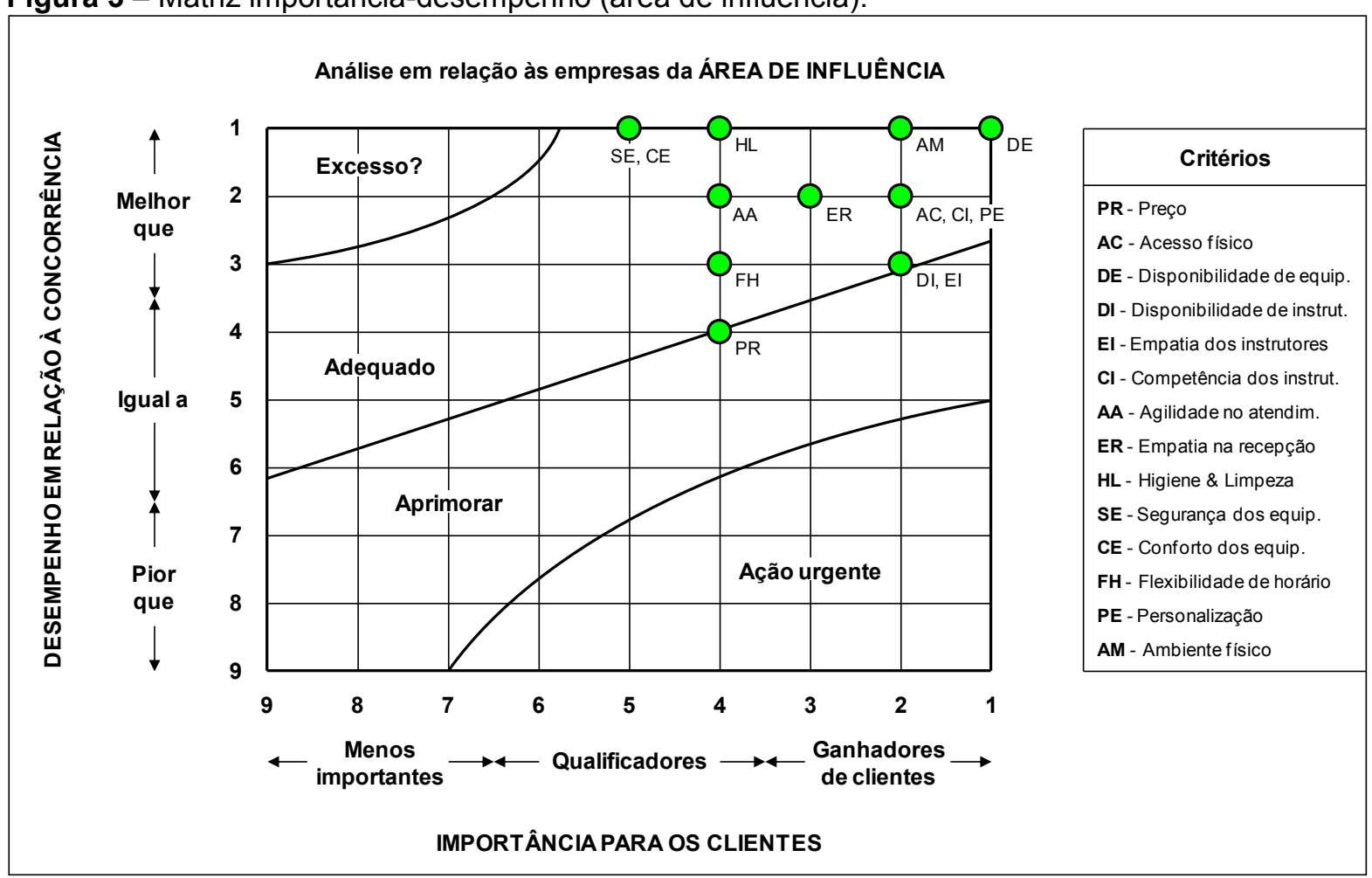

Fonte: Elaborado pelos autores.

Revista Produção Online. Florianópolis, SC, v.12, n. 1, p. 133-158, jan./mar. 2012. 
Figura 4 - Matriz importância-desempenho (melhores práticas).

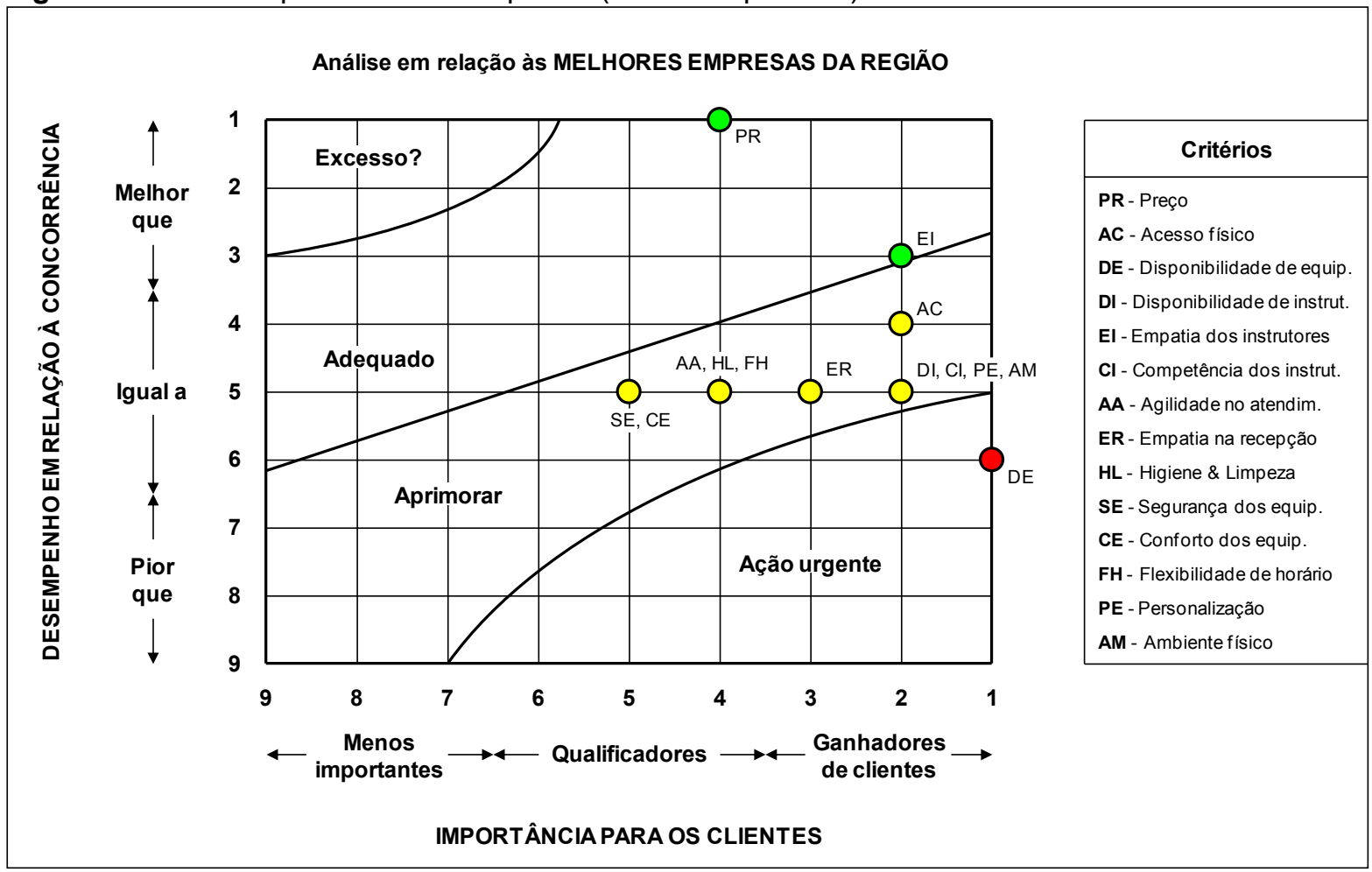

Fonte: Elaborado pelos autores.

Ainda na análise em relação à área de influência, outros dois critérios que ficaram no limite entre o "adequado" e o "aprimoramento" são a disponibilidade e a empatia dos instrutores. Um dos motivos que contribuíam para isso era a utilização total da capacidade produtiva da academia durante os horários de pico. De fato, um trade-off comum nas operações de serviços é que a qualidade no atendimento tende a diminuir com a maximização da capacidade.

Quando comparada com as melhores academias da região, a academia apresentou uma necessidade de melhoria em quase todos os critérios, sendo que a "disponibilidade de equipamentos" necessitava de uma melhoria urgente. Isso demonstrou que ainda havia um longo caminho a percorrer se a empresa quisesse se equiparar às melhores práticas.

A baixa disponibilidade de equipamentos era um problema que já vinha sendo observado pelos gerentes, principalmente na época de alta temporada, período em que os problemas de capacidade ficavam mais em evidência. $O$ fato mais curioso é que na análise em relação à área de influência esse critério ficou com o desempenho máximo, ou seja, ele estava adequado para a competição com os concorrentes diretos, mas ainda estava muito longe do nível que a academia Revista Produção Online. Florianópolis, SC, v.12, n. 1, p. 133-158, jan./mar. 2012. 
almejava chegar. Embora a situação atual aparentasse ser confortável, diante da estrutura da empresa e das previsões para o setor de fitness, a equiparação com as melhores práticas era fundamental para a sobrevivência de longo prazo do negócio.

\subsection{Análise das relações entre critérios}

Com a identificação das prioridades de melhoria nos CVP's, foi necessário conhecer as relações entre esses critérios. Para realizar essa tarefa, foi utilizada a matriz de relações entre critérios, evidenciando as relações de conflito (trade-off) e de apoio mútuo (figura 5).

Figura 5 - Matriz de relações entre os CVP's da academia.

\begin{tabular}{|c|c|c|c|c|c|c|c|c|c|c|c|c|c|c|}
\hline $\begin{array}{l}\text { Relações de: } \\
\text { X - CONFLITO } \\
\text { O - APOIO MÚTUO }\end{array}$ & 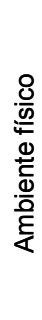 & 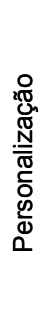 & 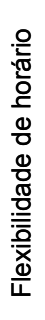 & 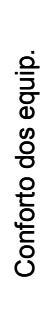 & 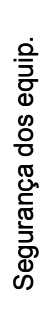 & 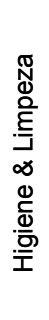 & 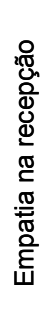 & 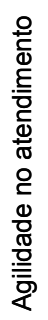 & 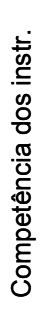 & 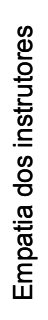 & 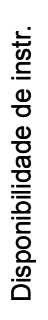 & 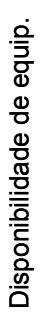 & 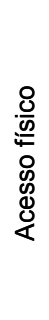 & 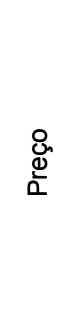 \\
\hline Preço & $\mathbf{x}$ & & & & & & $\mathbf{x}$ & $\mathbf{x}$ & $\mathbf{x}$ & & 0 & $\mathbf{x}$ & $\mathbf{x}$ & \\
\hline \multicolumn{15}{|l|}{ Acesso físico } \\
\hline Disponibilidade de equipamentos & $\mathbf{x}$ & & & & & & & 0 & & & & & & \\
\hline Disponibilidade de instrutores & & 0 & 0 & & & & & 0 & & & & & & \\
\hline Empatia dos instrutores & & & & & & & & 0 & 0 & & & & & \\
\hline Competência dos instrutores & & 0 & & & & & & 0 & & & & & & \\
\hline Agilidade no atendimento & & 0 & & & & & $\mathbf{x}$ & & & & & & & \\
\hline \multicolumn{15}{|l|}{ Empatia na recepção } \\
\hline Higiene \& Limpeza & 0 & & & 0 & & & & & & & & & & \\
\hline \multicolumn{15}{|l|}{ Segurança dos equipamentos } \\
\hline \multicolumn{15}{|l|}{ Conforto dos equipamentos } \\
\hline \multicolumn{15}{|l|}{ Flexibilidade de horário } \\
\hline \multicolumn{15}{|l|}{ Personalização } \\
\hline Ambiente físico & & & & & & & & & & & & & & \\
\hline
\end{tabular}

Fonte: Elaborado pelos autores.

De uma forma geral, os critérios prioritários não apresentaram trade-offs significativos que pudessem impedir sua melhoria. No entanto, a "disponibilidade de equipamentos", que foi uma melhoria urgente indicada pela matriz importânciadesempenho (melhores práticas), demonstrou uma relação de conflito com o "ambiente físico" que realmente não deveria ser ignorada. Esse trade-off chamou a atenção dos gerentes para o fato de que a melhoria da disponibilidade de

Revista Produção Online. Florianópolis, SC, v.12, n. 1, p. 133-158, jan./mar. 2012. 
equipamentos talvez tivesse que ser acompanhada por um investimento para a reforma das instalações, de maneira que o ambiente físico não ficasse prejudicado com um número maior de equipamentos no mesmo espaço.

\subsection{Análise critério-processo}

Nesta atividade foram analisadas as relações entre os CVP's e os processos relacionados com as operações da academia. Foram identificados oito processos nas operações da academia: instrução de musculação, instrução de ginástica, instrução de dança, instrução de personal training, avaliação física, recepção, limpeza e manutenção. Esses processos foram confrontados com os CVP's nas matrizes critério-processo, apresentadas nos quadros 5, 6 e 7.

Quadro 5 - Matriz critério-processo da academia.

\begin{tabular}{|c|c|c|c|c|c|c|c|c|c|}
\hline & & \multicolumn{8}{|c|}{ PROCESSOS } \\
\hline & & $\begin{array}{r}\text { INSTR. } \\
\text { MUSCUL. }\end{array}$ & $\begin{array}{l}\text { INSTR. } \\
\text { GINÁST. }\end{array}$ & $\begin{array}{l}\text { INSTR. } \\
\text { DANÇA }\end{array}$ & $\begin{array}{l}\text { INSTR. } \\
\text { PERSON. }\end{array}$ & $\begin{array}{l}\text { AVAL. } \\
\text { FISICA }\end{array}$ & RECEPÇÃO & LIMPEZA & $\begin{array}{c}\text { MANUTEN- } \\
\text { ÇÃO }\end{array}$ \\
\hline \multirow{14}{*}{ 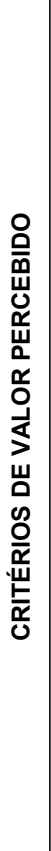 } & Preço & $\bullet$ & $\bullet$ & O & $\triangle$ & & $\bullet$ & $\bullet$ & $\triangle$ \\
\hline & \multicolumn{9}{|l|}{ Acesso físico } \\
\hline & Disponibilidade de equipamentos & $\bullet$ & O & & $\bullet$ & & & & $\bullet$ \\
\hline & Disponibilidade de instrutores & $\bullet$ & $\bullet$ & $\bullet$ & O & $\bullet$ & & & \\
\hline & Empatia dos instrutores & $\bullet$ & $\bullet$ & $\bullet$ & $\bullet$ & $\triangle$ & & & \\
\hline & Competência dos instrutores & $\bullet$ & $\bullet$ & $\bullet$ & $\bullet$ & $\bullet$ & & & \\
\hline & Agilidade no atendimento & $\bullet$ & $\bullet$ & $\bullet$ & $\bullet$ & $\bullet$ & $\bullet$ & & \\
\hline & Empatia na recepção & & & & & & $\bullet$ & & \\
\hline & Higiene \& Limpeza & & $\bullet$ & $\bullet$ & & & & • & \\
\hline & Segurança dos equipamentos & $\bullet$ & & & $\bullet$ & & & & $\bullet$ \\
\hline & Conforto dos equipamentos & $\bullet$ & & & $\bullet$ & & & & \\
\hline & Flexibilidade de horário & $\triangle$ & $\bullet$ & $\bullet$ & $\triangle$ & $\bullet$ & & & \\
\hline & Personalização & O & $\triangle$ & $\triangle$ & $\bullet$ & & & & \\
\hline & Ambiente físico & $\bullet$ & $\bullet$ & $\bullet$ & $\bullet$ & $\bullet$ & $\bullet$ & - & \\
\hline & - RELAÇÃO F & & O RELAC & O MÉDIA & & $\triangle$ RELA & ÃO FRACA & & \\
\hline
\end{tabular}

Fonte: Elaborado pelos autores. 
Quadro 6 - Matriz critério-processo ponderada (área de influência).

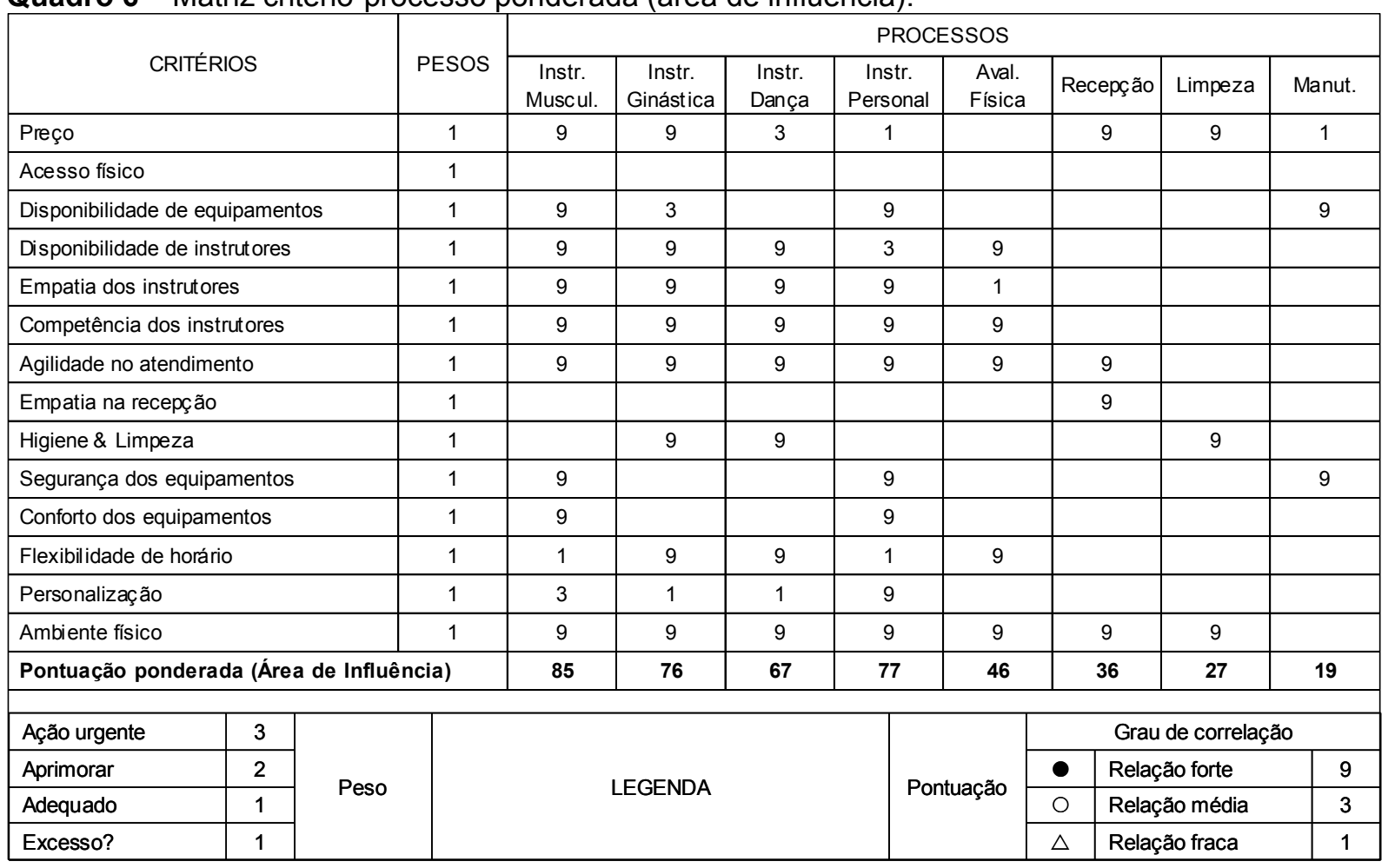

Fonte: Elaborado pelos autores

Quadro 7 - Matriz critério-processo ponderada (melhores práticas)

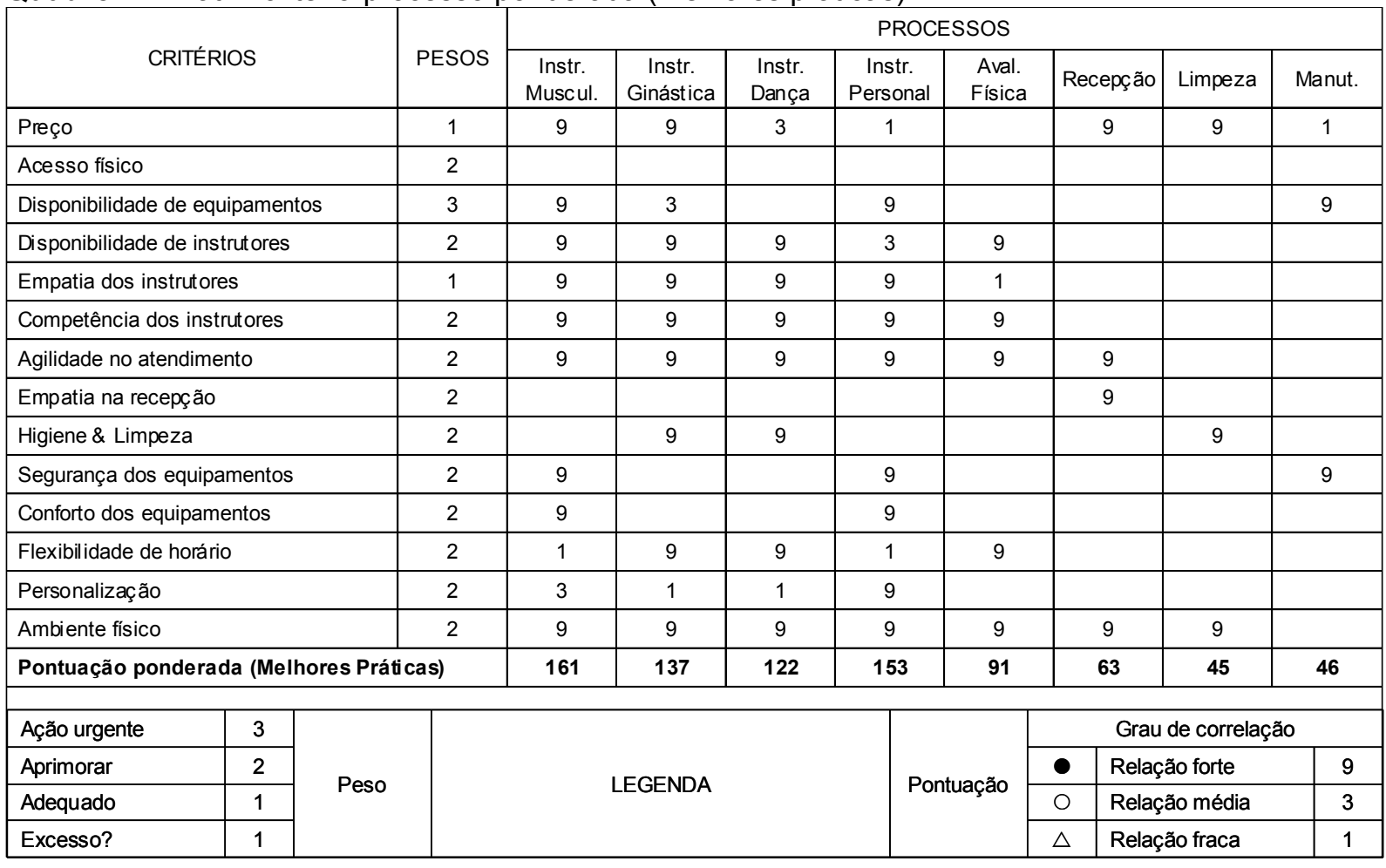

Fonte: Elaborado pelos autores

Revista Produção Online. Florianópolis, SC, v.12, n. 1, p. 133-158, jan./mar. 2012. 
Tanto na análise simples quanto na análise ponderada pelas duas óticas, ficou evidente a forte relação dos quatro processos de instrução (musculação, ginástica, dança e personal) com a maioria dos critérios de valor percebido. Esses resultados são justificáveis, pois aqueles são processos que estão relacionados com a atividade principal da academia. Desse modo, todos os processos de instrução poderiam ser considerados prioritários se fosse levada em conta a relação que eles possuem com os CVP's. Porém, o processo de instrução de musculação merece um destaque especial, pois ele é responsável pelo serviço de maior faturamento da empresa.

\section{CONSIDERAÇÕES FINAIS}

Este artigo descreveu uma análise detalhada dos critérios competitivos (definidos aqui como critérios de valor percebido - CVP's) das operações de uma academia de ginástica. Os resultados confirmaram que o estabelecimento de prioridades competitivas tem um papel fundamental no processo de formulação da estratégia de operações. De fato, a priorização dos aspectos que devem ser melhorados nas operações está incorporada no próprio conceito de estratégia de produção.

A análise dos CVP's da academia de ginástica ofereceu uma oportunidade ímpar para que a estratégia de operações da empresa fosse discutida. Embora os gerentes já tivessem uma noção de que a empresa ocupava uma posição de destaque em sua área de influência, a análise dos CVP's permitiu que eles confirmassem essa situação. Além disso, a análise possibilitou visualizar as alternativas estratégicas que a empresa teria pela frente para atingir o objetivo de equiparar seu desempenho com as academias de referência (best practices). Por exemplo, um dos desafios estratégicos que os gerentes deverão enfrentar ao caminhar em direção às melhores práticas será a manutenção de sua participação de mercado em sua área de influência, uma vez que os preços tendem a subir com o aumento dos custos relacionados com a melhoria das operações. Nesse caso, uma questão-chave que merece uma investigação mais detalhada é: As receitas geradas pela equiparação da academia com as melhores práticas compensariam a potencial perda de clientes da área de influência? 
Vale ressaltar que o modelo proposto para a análise de CVP's representa uma contribuição prática deste trabalho. Embora ele não traga nenhuma ferramenta que seja inédita, do ponto de vista científico, a estruturação da sequência de atividades do modelo fornece um roteiro que guia as ações dos gerentes de serviços na análise de operações similares. Outra contribuição deste artigo é a definição de critérios competitivos que unem a perspectiva do cliente à perspectiva das operações, uma vez que a participação do cliente nos processos de serviços torna desnecessária a distinção entre os objetivos internos (operações) e os requisitos de mercado (marketing).

Como este trabalho abordou essencialmente a visão orientada pelo mercado, recomenda-se para a continuidade da pesquisa a inclusão no modelo proposto da visão baseada em recursos, na qual a estratégia de produção passa a ser vista como uma atividade de desenvolvimento de competências nas operações. Desse modo, emerge uma pergunta de pesquisa que concilia as duas visões: Como a empresa poderá desenvolver competências para sustentar um desempenho superior em suas prioridades competitivas?

\section{REFERÊNCIAS}

ACUR, N.; BITITCI, U. Managing strategy through business processes. Production Planning \& Control, v. 14, n. 4, p. 309-326, 2003.

ARBORE, A.; BUSACCA, B. Rejuvenating importance-performance analysis. Journal of Service Management, v. 22, n. 3, p. 409-430, 2011.

BOYER, K. K.; LEWIS, M. W. Competitive priorities: investigating the need for tradeoffs in operations strategy. Production and Operations Management, v. 11, n. 1, p. 9-20, 2002.

CORREAA, H. L.; CAON, M. Gestão de serviços: lucratividade por meio de operações e de satisfação dos clientes. São Paulo: Atlas, 2002.

COUGHLAN, P.; COGHLAN, D. Action research for operations management. International Journal of Operations \& Production Management, v. 22, n. 2, p. 220-240, 2002.

DANGAYACH, G. S.; DESHMUKH, S. G. Manufacturing strategy: literature review and some issues. International Journal of Operations \& Production

Management, v. 21, n. 7, p. 884-932, 2001. 
DENG, W.; KUO, Y.; CHEN, W. Revised importance-performance analysis: threefactor theory and benchmarking. The Service Industries Journal, v. 28, n. 1, p. $37-$ $51,2008$.

EDEN, C.; HUXHAM, C. Action research for management research. British Journal of Management, v. 7, n. 1, p. 75-86, 1996.

FERDOWS, K.; DE MEYER, A. Lasting improvements in manufacturing performance: in search of a new theory. Journal of Operations Management, v. 9, n. 2, p. 168$184,1990$.

FITZSIMMONS, J. A.; FITZSIMMONS, M. J. Administração de serviços: operações, estratégia e tecnologia de informação. 4.ed. Porto Alegre: Bookman, 2005.

GARVIN, D. A. Manufacturing strategic planning. California Management Review, v. 35 , n. 4 , p. $85-106,1993$.

HALLGREN, M.; OLHAGER, J.; SCHROEDER, R. G. A hybrid model of competitive capabilities. International Journal of Operations \& Production Management, v. 31, n. 5, p. 511-526, 2011.

HAYES, R. H. et al. Operations, strategy and technology: pursuing the competitive edge. New York: John Wiley \& Sons, 2005.

HILL, T. Manufacturing strategy: text and cases. 2.ed. Burr Ridge: Irwin, 1994.

JIA, G. Z.; BAI, M. An approach for manufacturing strategy development based on fuzzy-QFD. Computers \& Industrial Engineering, v. 60, n. 3, p. 445-454, 2011.

JOHNSTON, R. The determinants of service quality: satisfiers and dissatisfiers. International Journal of Service Industry Management, v. 6, n. 5, p. 53-71, 1995.

KOCEVAR-WEIDINGER, E. et al. Why and how to mystery shop your reference desk. Reference Services Review, v. 38, n. 1, p. 28-43, 2010.

LIMA, E. P.; COSTA, S. E. G.; FARIA, A. R. Taking operations strategy into practice: developing a process for defining priorities and performance measures. International Journal of Production Economics, v. 122, n. 1, p. 403-418, 2009.

LIN, C.; SHER, P. J.; SHIH, H. Past progress and future directions in conceptualizing customer perceived value. International Journal of Service Industry Management, v. 16, n. 4, p. 318-336, 2005.

LIU, N.; ROTH, A. V.; RABINOVICH, E. Antecedents and consequences of combinative competitive capabilities in manufacturing. International Journal of Operations \& Production Management, v. 31, n. 12, p. 1250-1286, 2011.

MARTILLA, J. A.; JAMES, J. C. Importance-performance analysis. Journal of Marketing, v. 41, n. 1, p. 77-79, 1977. 
MELLO, S. C. B.; LEÃO, A. L. M. S.; SOUZA NETO, A. F. Uso conjunto de dois modelos cognitivos para a compreensão do processo de escolha do consumidor. Produção, v. 15, n. 1, p. 8-22, 2005.

PARASURAMAN, A.; ZEITHAML, V. A.; BERRY, L. L. A conceptual model of service quality and its implications for future research. Journal of Marketing, v. 49, n. 4, p. 41-50, 1985.

PARENTE, J.; KATO, H. T. Área de influência: um estudo no varejo de supermercados. RAE - Revista de Administração de Empresas, v. 41, n. 2, p. 4653, 2001.

PLATTS, K. W.; GREGORY, M. J. Manufacturing audit in the process of strategy formulation. International Journal of Operations \& Production Management, v. 10, n. 9, p. 5-26, 1990.

RIVIEZZO, A.; NISCO, A.; NAPOLITANO, M. R. Importance-performance analysis as a tool in evaluating town centre management effectiveness. International Journal of Retail \& Distribution Management, v. 37, n. 9, p. 748-764, 2009.

ROSENZWEIG, E. D.; EASTON, G. S. Tradeoffs in manufacturing? A meta-analysis and critique of the literature. Production and Operations Management, v. 19, n. 2, p. $127-141,2010$.

ROTH, A. V.; MENOR, L. J. Insights into service operations management: a research agenda. Production and Operations Management, v. 12, n. 2, p. 145-164, 2003.

SAMPSON, S. E.; FROEHLE, C. M. Foundations and implications of a proposed unified services theory. Production and Operations Management, v. 15, n. 2, p. 329-343, 2006.

SILVEIRA, G. J. C. Market priorities, manufacturing configuration, and business performance: an empirical analysis of the order-winners framework. Journal of Operations Management, v. 25, n. 6, p. 662-675, 2005.

SKINNER, W. Manufacturing - missing link in corporate strategy. Harvard Business Review, v. 47, n. 3, p. 136-145, 1969.

SKINNER, W. Manufacturing strategy: the story of its evolution. Journal of Operations Management, v. 25, n. 2, p. 328-335, 2007.

SLACK, N. The importance-performance matrix as a determinant of improvement priority. International Journal of Operations \& Production Management, v. 14, n. 5, p. 59-75, 1994.

SLACK, N.; LEWIS, M. Estratégia de operações. 2.ed. Bookman: Porto Alegre, 2009.

SPRING, M.; BOADEN, R. "One more time: how do you win orders?": a critical reappraisal of the Hill manufacturing strategy framework. International Journal of Operations \& Production Management, v. 17, n. 8, p. 757-779, 1997.

Revista Produção Online. Florianópolis, SC, v.12, n. 1, p. 133-158, jan./mar. 2012. 
TONTINI, G.; SILVEIRA, A. Identification of satisfaction attributes using competitive analysis of the improvement gap. International Journal of Operations \&

Production Management, v. 27, n. 5, p. 482-500, 2007.

WILSON, A. M. The role of mystery shopping in the measurement of service performance. Managing Service Quality, v. 8, n. 6, p. 414-420, 1998.

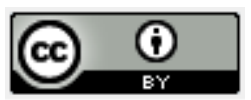

Artigo recebido em 23/10/2010 e aceito para publicação em 20/12/2011. 